УДК 821.161 .1 .0

\title{
Н.В. Гончарова
}

\section{УРОКИ А.И. ГАЛИЧА В СТАНОВЛЕНИИ ЛИТЕРАТУРНО-ЭСТЕТИЧЕСКИХ ВЗГЛЯДОВ А.В. НИКИТЕНКО}

\begin{abstract}
Рассматривается влияние А.И. Галича на становление основной проблематики критического творчества А.В. Никитенко. Категория изящного, активно входящая в лексикон русской эстетики, формирует такие понятия, как идейность искусства, воплощение идеи в образах, свобода творчества. Прослежено, как решаются эти проблемы Галичем и Никитенко. Учитель и ученик по-разному оценивают противостояние классицизма и романтизма в литературном процессе начала XIX в., а также делают попытки предсказать ход дальнейшего развития русской литературы.

Ключевые слова: идейность искусства; художественный образ; свобода творчества; классицизм; романтизм; философский историзм; А.И. Галич; А.В. Никитенко.
\end{abstract}

Александр Васильевич Никитенко преподавал русскую словесность в Санкт-Петербургском университете с 1832 по 1864 г., по сути, в период самоопределения русской литературы, в эпоху бурных эстетических споров о ее национальном своеобразии. Теоретические работы А.В. Никитенко отражают важнейшие процессы того времени, происходившие в науке о литературе и словесности. В поле его зрения оказывается целый ряд актуальных вопросов по мере их возникновения. Проблеме научного изучения литературы посвящена речь Никитенко «О необходимости теоретического или философского исследования литературы» (1836). Вопрос о месте поэзии в искусстве - в центре его диссертации «О творящей силе в поэзии, или О поэтическом гении» (1837). Поиски теоретических оснований для литературной критики определили пафос речи «О критике» (1842). Самоопределение национальной русской литературы, проблема народности стали предметом рассмотрения в статьях «О характере народности в древнем и новейшем искусстве» (1846) и «О современном направлении русской литературы» (1847). Наконец, историю становления нового направления в литературе - peaлизма - Никитенко осмысливал в теоретической работе «Мысли о реализме» (1872).

Весь этот комплекс критико-теоретических работ приобретал методологический характер, так как способствовал выработке новых эстетических оснований для историко-литературного процесса 1830-1860-х гг. Вместе с тем идеи Никитенко имели и прикладное значение: они активно входили в систему университетского образования и определяли формирование новой генерации деятелей русской культуры. Достаточно сказать, что одним из его учеников был Н.Г. Чернышевский, автор диссертации «Эстетические отношения искусства к действительности», тема которой была одобрена профессором. Поэтому вопрос о генезисе эстетических взглядов Никитенко, о его связи с предшествующей традицией, прежде всего с направлением русской философской эстетики, приобретает свою актуальность в общем контексте сегодняшних размышлений о феноменологии филологического знания.

Определяя лицо Никитенко-критика и эстетика молодой Ю.Ф. Самарин в статье «О мнениях “Современника" исторических и литературных» (1847) пи- сал: «Г. Никитенко в современной литературе лицо довольно значительное. Он стоит особняком от всех и значит в ней сам по себе. <..> он неожиданно открывает $<\ldots>$ новые стороны или так оригинально и метко обозначает уже известное, что слова врезаются в памяти» [1. С. 153]. Это суждение одного из виднейших представителей молодого поколения, публициста и литературного критика говорит о многом: А.В. Никитенко занимал свое и особое место в русской эстетике и критике.

Никитенко окончил философско-юридический факультет Петербургского университета, где помимо изучения политической экономии и философии лекции читали профессора словесности, к которой он уже в молодости имел необычайный интерес. В СанктПетербургском университете, который стал таковым лишь в 1819 г., преподаватели совмещали по несколько дисциплин. Я.В. Толмачев читал философию на философско-юридическом факультете, а с 1824 г. перешел на классическую словесность. Профессор Н.И. Бутырский был одним из представителей нового мировоззрения, учился за границей, слушал лекции Бутервека, чьи эстетические установки и понятия об изящных искусствах переносил на русскую аудиторию. Н.И. Бутырский, по словам Никитенко, снискал «репутацию первого из современных в России профессоров словесности» [2. С. 86-87]. Однако он одновременно читал лекции по словесности и политической экономии, пока окончательно не перешел на кафедру политэкономии. Поэтому переход Никитенко с преподавания политической экономии на преподавание словесности был вполне в духе времени, этому способствовали и широкие познания в науках, и понимание словесности как проявления главных сил мировой и национальной культуры, совмещенное с пониманием философии, которая «занимается общими идеями, <..> ставит их во главе всякого знания и высшей умственной деятельности $<\ldots>$ Без нее образованию недостает ни глубины, ни величия» [3. С. 2].

Расцвет немецкой идеалистической философии, уроки Шеллинга актуализировали процесс становления в 1820-1830-х гг. феномена русской философской эстетики, при которой, по словам Ю.В. Манна, «философская предоснова восприятия искусства <..> ощущается недостаточной и уступает место целенаправленному включению искусства в философское 
наукоучение» [4. С. 5]. И университетская наука в лице ее лучших представителей восприняла эти «плоды просвещения». Уже со студенческой скамьи Никитенко оказался свидетелем изменений в методах и взглядах на словесность. В процессе противостояния французского классицизма и немецкого романтизма философские идеи и эстетические воззрения проникали в сознание русских людей и выражались в первых ярких трудах любомудров и молодых шеллингианцев.

Большое место в формировании русского литературоведения занимало историческое направление, которое развивал в своем преподавании П.А. Плетнев. Известно, что он был оппонентом на защите диссертации Никитенко в 1837 г., и его позиция благотворно сказалась на развитии будущего профессора, несмотря на последующие разногласия. Оба они развивали идеи историзма и народности, воплощающие передовые направления в литературе.

Самым значительным наставником в формировании Никитенко был Александр Иванович Галич. Философ по образованию и по призванию, лицейский учитель А.С. Пушкина, профессор Петербургского университета, Галич являлся проводником немецкой идеалистической философии и эстетической мысли в России. Основав свою философию на учении Ф. Шеллинга, он «предвосхищал и выявлял ту проблематику, которая станет генеральной в дальнейшем развитии эстетики» [5. С. 141]. Исследователями признано влияние Галича на возникновение московского кружка любомудров и развитие идей шеллингианской философии среди передовой молодежи.

Никитенко учился непосредственно у А.И. Галича, когда профессор уже ушел с университетской кафедры, посещал его лекции на дому и, конечно, внимательно изучал его труды. В библиотеке Никитенко есть пять изданий Галича, три из которых имеют множество помет. Это главные книги Галича, составляющие суть его учения. «История философских систем» (кн. 1-2. СПб., 1818-1819) - первая русская книга по истории философии. В ней впервые на русском языке представлены идеи Ф. Шеллинга (по части философии тождества). «Опыт науки изящного» (1825) - систематическое изложение романтической, идеалистической эстетики применительно к искусству и литературе. «Картина человека» (1834) - антропологическое исследование, в котором эстетические действия получают психологическое объяснение.

Непосредственно литературные вопросы рассматриваются в «Опыте науки изящного», в котором Галич размышлял над проблематикой художественного мышления и творчества. Масштаб этого сочинения Галича точно определен в анонимной рецензии, появившейся сразу после выхода «Опыта...»: «...скажем, - писал критик, - что мы удовлетворяемся сим отечественным произведением более, нежели каким-либо из иностранных, на тех же самых простых началах основанных» [6. С. 288]. Опираясь на достижения европейской философии и эстетики, автор посвящает свой трактат развитию русской эстетической мысли. В заключение предисловия он пишет: «Я заплатил свой долг науке, пояснив ее начала, обозначив границы и показав способ решить ее задачи» [7. C. XVI].

«Опыт» Галича Никитенко получил в дар от автора и по прочтении отметил в тексте 13 фрагментов, из которых четыре касаются сущности изящного как предмета, удовлетворяющего эстетические потребности человека. Отмечены также места, в которых даются характеристика изящного и объем понятия. Никитенко много размышлял об этом: в его архиве (PO ИРЛИ) сохранились целые тетради, фиксирующие его мысли об изящном, о его природе, проявлениях в тексте произведений, задачах и значении для литературы. Этому посвящены, например, такие работы, как «Опыты и наблюдения по части философии изящного и словесности» (кн. I. 1835-1839), «Учение об изящном» [8]. Свои мысли и наблюдения он впоследствии использовал в практике преподавания словесности и в сочинениях по эстетике и критике.

В своем труде Галич в первую очередь объясняет мысль об изящном «как о чувственно-совершенном проявлении значительной истины свободной деятельностью нравственных сил гения» [7. С. ХІІ]. Под «значительной истиной» автор понимал божественную идею, выдвигая, таким образом, проблему идейной сущности искусства, которая была воспринята из философии Ф. Шеллинга. В книге Карла Фридриха Бахмана (ученика Шеллинга) «Всеобщее начертание теории искусств», которая есть в библиотеке Никитенко, говорится: «Изящное есть воплощенная идея, <...> тождество бесконечного с конечным» [9. С. 44]. Это произведение немецкого эстетика, переведенное в 1832 г. М. Чистяковым, получило осмысление в развернутой рецензии Н.И. Надеждина на страницах журнала «Телескоп» (1832. Ч. VIII. № 5). Подчеркивая органичную связь книги Бахмана с идеями новейшей немецкой философии, он писал: «Она заимствовала у Шеллингова трансцендентализма идеальное одушевление, коим просветлены все ее взгляды» [10. С. 318]. Вслед за немецкими философами Галич утверждал: «Все изящное есть идеальное, образцовое, то есть такое, в котором устраняются случайные черты, временные и местные ограничения, а удерживается только существенный характер целого рода или класса» [7. С. 25].

Понятие об идеале Никитенко воспринял через трактат Бахмана и книгу Галича. Среди отмеченных им в «Опыте» отрывков в трех речь идет об идеальном. Это и идеи, «составляющие внутреннюю, невидимую сущность вещей» [Там же. С. 19]; и идеальное как «Всесовершеннейшее, представляемое фантазией и созерцаемое умственными очами» [Там же. С. 53]. В своей диссертации Никитенко связывает понятия изящного и идеального: «чувство изящного» - «идея чистой красоты, или... идея жизни в ее идеальном и вместе гармоническом настроении» [11. С. 11]. Размышления Никитенко над текстом «Опыта» Галича выразились также в карандашной записи на заднем форзаце книги: “Изящное, Поэзия души есть у всякого; многие даже могут сообщать её другим - но только те творят оное, которые передают его в определенных органических формах, удерживаю- 
ицх идею изящного на известном месте в ряду явлений идеальной жнзни» [12. С. 401]. Таким образом, по мнению читателя книги Галича, идеальная жизнь удерживается в определенных органических формах, т.е. в художественных образах.

В «Опыте» Галича мы видим, что он обращал внимание, каким образом идеал осуществляется в определенных формах, низводится «из области идей в жизнь действительную» и подчиняется «как формам, так и законам чувственности. Формы же всякого явления суть пространство (или место) и время, а законы: разнообразие, соразмерность и соединение в один состав» [7. С. 34]. Это место в книге Галича Никитенко отметил знаком NB и подчеркнул. Для Никитенко тема происхождения художественного образа была принципиальной, он активно развивал её в своей эстетической системе. По его словам, «...в изящном произведении соединяются два элемента - идеальное и действительное, дух и плоть, небесное и земное» [13. С. 542]. С этим он связывал вопрос о природе художественного обобщения: «Материалы для самих образов фантазия находит в природе и человечестве; но они выходят из глубины ее с таким характером и организацией, каких ни в природе, ни в человечестве не бывает. Это идеалы» [11. С. 20].

Никитенко более подробно, чем учитель, прослеживает путь от идеала к образу. Если Галич говорил лишь об «...общей судьбе идей, выходящих за границу всякого данного или существующего явления» [7. C. 24], то Никитенко развивает эту мысль. По его мнению, творческие силы в человеке пробуждаются от стремления «жить не только своей отдельной жизнью, жизнью своего общества, века, но - жизнью человечества <..> душа его должна возвыситься над многосложными стихиями жизни, <..> воздвигнуть из них новую природу». Это идея, которой нужно воплотиться в образ, обрести форму. И Никитенко продолжает: «Если в возвышенном своем полете он (гений) мог сначала удалиться на необъятное расстояние от действительного порядка вещей, то здесь он снова в него входит, примиряется с ним, заставляя свои создания жить по законам действительной жизни, <..> по законам природы» [Там же. С. 20-21].

Воплощенное в форме изящное Галич называет Прекрасным, которое встречает свою противоположность в дурном, и эстетические предметы, «двигаясь между $<\ldots>$ крайностями $<\ldots>$, принимают в том и другом участие» [7. С. 36]. Галича особенно привлекает возникновение комического, смешного, основанного «не на гармонии явлений, а на расстройствах оных, то есть на несовершенствах», он очень обобщенно показывает построение комического образа с помощью гротеска, пародии и «юморизма» [Там же. С. 45-50].

Никитенко, в свою очередь, прослеживает создание образов в конкретных художественных произведениях великих писателей: «Посмотрите, какая должна быть свобода и какая мощь в нравственных силах, чтобы лучшую, очаровательнейшую прелесть, нежную и вместе роскошную сторону человеческой жизни перелить в одно неделимое существо и сказать ему: живи, - и вместе с тем Шекспир это сделал, он создал Юлию» [11. С. 15-16]. Здесь имеется в виду образ Джульетты: трагедия Шекспира в переводе на русский язык под заглавием «Ромео и Юлия» публиковалась отрывками в альманахе «Северные цветы на 1830 год». Обращаясь к «Фаусту» Гете, Никитенко показывает глубину страстей, борение человека и подчеркивает: «Здесь так много жизни, взятой из природы и судьбы человеческой, что кажется нескольким векам не исчерпать бы этой глубины страстей, - но перед вами Фауст великого Гете, и эти века сократились для вас в пространстве одной жизни, их богатство разлилось в биении сердца нескольких лиц» [Там же. С. 17]. Для Никитенко идея и образ являются основой художественного произведения. Он уделил этому вопросу много внимания в диссертации «О творящей силе в Поэзии», и в дальнейшем он имел возможность выражать свои знания в преподавательской практике, прослеживать создание образов писателями в своей критической деятельности.

Завершая первую часть «Опыта», Галич уточняет свое определение изящного: художественное произведение «...происходит там, где свободный гений человека $<\ldots>$ запечатлевает божественную, по себе значительную и вечную идею в самостоятельном, чувственно-совершенном, органическом образе» [7. С. 75-76]. В данном определении обозначается еще одна проблема: свободная деятельность художника. По словам Галича, изящное имеет черты самостоятельного бытия, оно «не может служить никаким сторонним видам и имеет свою цель само в себе» [Там же. С. 20].

Трезвое понимание свободы находится в основе понятия художественного творчества. «В разумном толковании идея художественной свободы и личного достоинства художника - великий культурный шаг сравнительно с ремесленническим словесным кропанием и писательским рабством классической эпохи» [14. C. 302]. Тему свободы поэта решал ученик Галича А.С. Пушкин на протяжении всего своего творчества, эта проблема поставлена им широко и многогранно.

Для Никитенко этот вопрос связан с позицией художника в новой реальности, с его самоопределением. Среди помет Никитенко в книге Галича есть два места о свободе художника, а именно, что творчеству присуща «черта бескорыстия», а также об отрицательной роли назидательной функции изящного, которая «...необходимо предполагается во всяком прекрасном предмете» [7. С. 21-22]. Впоследствии некоторые критики незаслуженно обвиняли Никитенко в приверженности к теории «чистого искусства». Но в своих работах он вслед за Галичем прежде всего отстаивал право художника на свободное творчество. Он называет свободу одним из главных эстетических свойств гениального произведения, которое существует «...для того, чтобы привести у вас в забвение всякую цель, - чтобы вы хотя бы на минуту перестали быть рабами ваших мелких страстей и сделались людьми, ощутили в себе сладость полного человеческого существования. Все в начинаниях наших <..> эгоизм - только Поэзия не знает его» [11. С. 37].

Однако Никитенко не просто констатирует свободу художника, а говорит об ответственности, о долге 
«не изменять верховным требованиям» человечества и природы, не употреблять своей свободы во зло [13. С. 544]. Общество «должно иметь нравственное ручательство» от литературы, иметь возможность охранять «святыню вкуса от осквернения нечистой мысли и нечистых уст» [Там же. С. 545]. И такую возможность дает критика, которая «во дни тревожного состояния вкуса должна ополчиться против заблуждений» [Там же]. Здесь Никитенко идет дальше Галича, он поднимает проблему личной ответственности художника и права общества защищать свои нравственные устои с помощью критики.

Итак, из 13 помет Никитенко в книге Галича четыре касаются сущности изящного, три - вопроса об идеальном, один отчеркнутый фрагмент обращен к теме образной сущности искусства и две пометы обращены к идее свободы творчества. Таким образом, можно говорить о системности помет Никитенко, абсолютное их большинство (10 из 13) непосредственно касается вопросов, вытекающих из определения изящного. Общее направление мысли у Галича и Никитенко совпадало, что вполне естественно для учителя и ученика. Но во многом ученик шел дальше своего учителя, разрабатывая вопросы образности, свободы на практическом материале и отвечая на запросы времени и общества.

Книга А.И. Галича «Опыт науки изящного» сыграла еще одну очень важную роль в развитии отечественной словесности. В ней было предпринято научное обоснование теории романтического искусства, которое уже с конца XVIII - начала XIX в. проникало в русскую литературу, но не имело своей теории. Галич впервые попытался «сформулировать новые явления в жизни поэзии» [15. С. 116]. Его рассуждения «...давали возможность русскому читателю разобраться в том литературном перевороте, который из Европы проник в русскую литературу, <..> объяснили сущность романтической поэзии» [Там же. С. 112].

Галич раскрывает отличия греческой поэзии (классического, нормативного искусства) от романтической поэзии (нового искусства). По словам Галича, «...характер искусства древних есть жизнь внешняя, натуральная, а характер искусства новых - внутренняя, духовная» [7. С. 53], поэтому для пластического искусства древних «все настоящее есть благо <..> и составляет цель жизни, в которой легко успокаиваются желания, ограниченные минутными наслаждениями и не простираемые в отдаленную будущность», а новоевропейский дух «не прилепляется к тщете земного бытия и скоротечных радостей, а устремляет нравственные свои помыслы и желания к беспредельной и вечной существенности» [Там же. С. 54]. Говоря о классическом искусстве, автор берет за образец древнегреческую культуру, на которой основывался и французский классицизм. Целью Галича было научно обосновать существование нового европейского искусства, для этого он поставил его в один ряд с греческим. Идея «поэтической универсальности», высказанная в «Опыте» Галича, состояла в том, что красота изменяется сообразно с историческими и местными условиями, эта идея полностью противоречила пред- ставлению классицизма о красоте как раз и навсегда заданной категории. Мысль об изменении понятий о красоте приводила к понятиям «о движении идеи, мирового духа и выводимой отсюда смене периодов истории» [4. С. 16]. В связи с этим Ю.В. Манн говорил об особой форме историзма - философском историзме, наметки которого встречались с начала 1920-х гг. в статьях Д. Веневитинова, В. Одоевского, С. Шевырева, а позднее - И. Киреевского, Н. Надеждина, В. Белинского [Там же. С. 16-19]. Приоритет этой теории неизменно отдается Галичу, а начиналась она с немецких источников - эстетических учений Бутервека, Аста, Бахмана. И хотя многие исследователи говорят о несамостоятельности учения Галича, однако, по словам И. Замотина, «Галичу можно поставить в заслугу и то, что он, хотя бы с голоса $<\ldots>$ немецких теорий словесности, провозгласил у нас важный принцип “универсальности поэтической” в то время, когда классицизм делал еще усилия задержать успехи романтизма» [15. С. 110]. Таким образом, Галич стоял у истоков русской философской эстетики, осмысления результатов и итогов «французского» и «немецкого» подходов к искусству. Развивая метод философского историзма, он видел третью форму искусства после классицизма и романтизма в слиянии двух первых и назвал ее «романтической пластикой». Эти прогрессивные для того времени мысли оказали влияние на развитие последующей эстетики.

Выразителем древней поэзии Галич считал Гомера, а для иллюстрации основных мотивов романтической поэзии он приводит слова из стихотворения В.А. Жуковского «Таинственный посетитель», таким образом, по сути, поставив поэта во главе романтического направления в русской литературе [7. С. 55].

Никитенко в своей работе о В.А. Жуковском уже более резко, по сравнению с Галичем, противопоставляет два направления в литературе. Он характеризует классическую литературную школу Франции как легкомысленную и поверхностную. Эта школа «не знала сущности красоты, но знала тайну украшений», в ней «идея и форма разошлись друг с другом, и последняя стала во главе эстетических движений» [16. С. 5]. Напротив, новоевропейское направление в литературе основалось на самобытных литературных движениях Англии и Германии и на христианском искусстве, «лучшие умы начало духовное признали основной стихией всякого художественного создания» [Там же. C. 7]. Никитенко пишет о значении В.А. Жуковского во всеобщем процессе смены ориентиров с французского метода на немецкий, о его назначении «уже готовые творения» западной мысли оживотворить «новым духом в другой сфере мысли и слова», в условиях русской литературы [Там же. С. 9].

Никитенко писал свою статью о Жуковском в 1853 г., уже после отзыва В. Белинского на «Очерки русской литературы» Н. Полевого, в котором было высоко оценено творчество Жуковского как романтика. Никитенко не согласен с общепринятым мнением, что Жуковский - «по преимуществу романтик» [17. С. 507], он вообще не высоко ставит романтизм «с его детской наивностью и фантастическими видениями» 
[16. С. 32] и пытается нивелировать этот термин. Он утверждает: «Если Жуковский и начал с романтизма, то после он далеко оставил его за собою, и услуга, оказанная им русской словесности, состоит не в том, что он сообщил ей романтический характер, а в том, что он возвел ее к мысли и идеалу» [Там же. С. 33]. Никитенко увидел в творчестве Жуковского жизнь и природу, с которой начинается истинная поэзия, «он показал, что за вдохновением надобно обращаться не к музам, а к природе и жизни» [Там же. С. 17]. Жуковский «...первый был поэтом в прямом художественном смысле этого слова», в творчестве которого господствовала идея «чистой красоты» [Там же. С. 4].

Никитенко называет Жуковского поэтом «идеальной действительности», предлагая философское понятие «идеализм» внедрить в литературный процесс, что явилось новым поворотом для философской эстетики, которая до этого использовала явления искусства для осмысления философской действительности. В то время Никитенко не был услышан, однако много позднее исследователи стали обращаться к понятию идеализма, осмысляя прошлое русской литературы. Так, И.И. Замотин в своем фундаментальном труде «Романтический идеализм в русском обществе и литературе 20-30-х гг. XIX столетия» (1907) усматривает связь идеалистического мировоззрения русских писателей с художественным творчеством. Затем П.Н. Сакулин в двухтомной монографии «Из истории русского идеализма» (1913) представил широчайшую картину идеалистического движения русской жизни через творческий путь В.Ф. Одоевского. Таким образом, Никитенко оказался первым, кто обнаружил внутри литературного процесса явления идеалистической философии.

По мнению Никитенко, лишь с идеализма Жуковского началась настоящая поэзия, и лишь после него стал возможен метод «поэтического реализма» «...как ни мало кажутся похожими на Жуковского Пушкин и Гоголь, но то верно, что он приготовил им путь и связан с ними прагматически в истории нашей поэзии» [16. С. 15]. Поиски нового вида искусства, нового метода литературы в традиции философской эстетики основывались на идеях шеллингианства. Так, Галич, Веневитинов и другие видели «третью» форму искусства в синтезе двух первых. В процессе переосмысления категорий немецкой эстетики произошел выход за границы этой парадигмы, и дальнейшее развитие искусства мыслилось как поиск не «третьей», а новой формы поэзии, принципиально иной. Никитенко в статье о Жуковском обнаружил стремление «осмыслить и обосновать реалистические перемены в русской литературе» [4. С. 302].

Таким образом, мы видим, что наследие Никитенко, как и Галича, вписывается в явление, называемое философской эстетикой. Развивая идеи своего учителя, он пытался увидеть эволюцию и переосмыслить явления философской эстетики, его стремление выявить «органические формы» новой поэзии в контексте нового философского опыта помогало ему найти точки соприкосновения эстетики с университетской наукой.

\section{ЛИТЕРАТУРА}

1. Русская эстетика и критика 40-50-х годов ХІХ века / подгот. текста, вступ. ст. и прим. В.К. Кантора, А.Л. Осповата. М., 1982.

2. Никитенко А.В. Дневник. М., 1955. Т. 1.

3. Никитенко А.В. Александр Иванович Галич // Журнал Министерства народного просвещения. 1869. Ч. CXLI.

4. Манн Ю.В. Русская философская эстетика (1820-1830-е годы). М., 1969.

5. Каменский 3.А. А.И. Галич. М., 1995.

6. Русские эстетические трактаты первой трети XIX века : в 2 т. М., 1974. Т. 2.

7. Галич А.И. Опыт науки изящного. СПб., 1825.

8. РО ИРЛИ. Фонд Никитенко. № 18112, № 18286.

9. Бахман. Всеобщее начертание теории искусств Бахмана / пер. с нем. М. Чистякова. М., 1832. Ч. 1.

10. Надеждин Н.И. Литературная критика. Эстетика / вступ. ст., сост. и коммент. Ю.В. Манна. М., 1972.

11. Никитенко A.B. О творящей силе в поэзии, или О поэтическом гении. СПб., 1836.

12. Колосова Г.И. Книга как источник изучения личностных отношений А.В. Никитенко и А.И. Галича // Информационное обеспечение науки: новые технологии : сб. науч. тр. / отв. ред. П.П. Трескова ; сост. О.А. Оганова. Екатеринбург, 2012. С. $398-404$.

13. Никитенко А.В. Речь о необходимости теоретического или философского исследования литературы // Журнал Министерства народного просвещения. 1837. № 3.

14. Иванов И. История русской критики. СПб., 1898. Ч. 1-2.

15. Замотин И.И. Романтизм двадцатых годов ХІХ столетия в русской литературе. СПб. ; М., 1908. Т. I.

16. Никитенко А.B. Василий Андреевич Жуковский со стороны его поэтического характера и деятельности. СПб., 1853.

17. Белинский В.Г. Полн. собр. соч. : в 13 т. М., 1953. Т. 3 : Статьи и рецензии.

Статья представлена научной редакцией «Филология» 25 марта 2015 г.

LESSONS OF A.I. GALICH IN THE FORMATION OF LITERARY AND AESTHETIC VIEWS OF A. NIKITENKO Tomsk State University Journal, 2015, 394, 15-20. DOI 10.17223/15617793/394/3

Goncharova Natalia V. Tomsk State University (Tomsk, Russian Federation). E-mail: Nauchka@mail.ru

Keywords: moral intelligence of art; artistic image; freedom of creativity; classicism; romanticism; philosophical historicism; A.I. Galich; A.V. Nikitenko.

A.V. Nikitenko read lectures on Russian literature at St. Petersburg University from 1832 to 1864, during the period of selfdetermination of Russian literature in the era of violent disputes about its national peculiarity. The most significant mentor in the formation of Nikitenko was a Professor of Philosophy at St. Petersburg University, A.I. Galich, he was the conductor of German idealism in Russia. In the book of Galich Experience of the Science of Nicety, the category of nicety formed such notions as ideological art, embodiment of idea in the image, freedom of creativity. Nikitenko formed his idea about the ideal through Galich's book, but he analyzed the way from the ideal to the image in more details than his teacher. Galich briefly explained the origin of the 
image of the comic; Nikitenko, in turn, studied the creation of images in specific works of great writers (Shakespeare and Goethe). Galich posed the problem of freedom of the artist; Nikitenko raised the problem of personal responsibility of a free artist and the right of society to protect its moral foundations using criticism. The general line of thought of Galich and Nikitenko coincided, but in many respects the disciple moved further than his teacher, developing questions of figurativeness, freedom on the practical material and answering the needs of the time and society. Galich's book Experience of the Science of Nicety played an important role in the development of Russian literature, it is an attempt to scientifically justify the theory of romanticist art. Galich showed differences between the classical normative art and the new romantic art. The idea of "poetic universality" Galich expressed was that beauty varies according to historical and local conditions. This idea led to a particular form of historicism: philosophical historicism. Galich was at the beginnings of Russian philosophical aesthetics, of understanding of the results and totals of the "French" and "German" aesthetic methods. In general course of philosophical historicism, he saw the third form of art after classicism and romanticism in the merger of the first two, and called it "romanticist plastic arts." These progressive for its time thought had an impact on the further development of aesthetics. In his article about V.A. Zhukovsky, Nikitenko contrasted more sharply, compared to Galich, two directions in the literature: the classic literary school of France and the new European trend in literature. Nikitenko wrote about the significance of V.A. Zhukovsky in the overall process of reorientation from the French to the German method, and claimed that Zhukovsky "was the first poet in the direct artistic sense of the word", that Zhukovsky's idealism prepared the way for the poetic realism of Pushkin and Gogol.

\section{REFERENCES}

1. Kantor V.K., Ospovat A.L. (eds.) Russkaya estetika i kritika 40-50-kh godov XIX veka [Russian aesthetics and criticism of 1840 50s]. Moscow: Iskusstvo Publ., 1982. 544 p.

2. Nikitenko A.V. Dnevnik [Diary]. Moscow: Goslitizdat Publ., 1955. V. 1, 542 p.

3. Nikitenko A.V. Aleksandr Ivanovich Galich [Aleksandr Ivanovich Galich]. Zhurnal Ministerstva narodnogo prosveshcheniya, 1869 , pt. CXLI.

4. Mann Yu.V. Russkaya filosofskaya estetika (1820-1830-e gody) [Russian philosophical aesthetics (1820-1830s)]. Moscow: Iskusstvo Publ., 1969. 304 p.

5. Kamenskiy Z.A. A.I. Galich [A.I. Galich]. Moscow: IFRAN Publ., 1995. 229 p.

6. Russkie esteticheskie traktaty pervoy treti XIX veka: $v 2$. [The Russian aesthetic treatises of the first third of the 19th century: in 2 v.]. Moscow: Iskusstvo Publ., 1974. V. 2,

7. Galich A.I. Opyt nauki izyashchnogo [Experience of the science of nicety]. St. Petersburg, 1825.

8. Manuscript Department of the Institute of Russian Literature, RAS (RO IRLI). Nikitenko Fund, no. 18112, no. 18286.

9. Bachmann K.F. Vseobshchee nachertanie teorii iskusstv Bakhmana [The general description of Bachmann's theory of art]. Translated from German by M. Chistyakov. Moscow, 1832. Pt. 1.

10. Nadezhdin N.I. Literaturnaya kritika. Estetika [Literary Criticism. Aesthetics]. Moscow: Khudozhestvennaya literatura Publ., $1972.576 \mathrm{p}$.

11. Nikitenko A.V. O tvoryashchey sile v poezii, ili O poeticheskom genii [On the creative power of poetry, or about poetic genius]. St. Petersburg, 1836. 41 p.

12. Kolosova G.I. Kniga kak istochnik izucheniya lichnostnykh otnosheniy A.V. Nikitenko i A.I. Galicha [The book as a source of study of personal relationships of A.V. Nikitenko and A.I. Galich]. In: Treskova P.P. (ed.) Informatsionnoe obespechenie nauki: novye tekhnologii [Informational support of science: new technology]. Ekaterinburg, 2012, pp. 398-404.

13. Nikitenko A.V. Rech' o neobkhodimosti teoreticheskogo ili filosofskogo issledovaniya literatury [Speech on the need for a theoretical or philosophical research of literature]. Zhurnal Ministerstva narodnogo prosveshcheniya, 1837, no. 3.

14. Ivanov I. Istoriya russkoy kritiki [History of Russian criticism]. St. Petersburg, 1898. Pt. 1-2.

15. Zamotin I.I. Romantizm dvadtsatykh godov XIX stoletiya v russkoy literature [History of Russian criticism]. St. Petersburg; Moscow, 1908. V. I.

16. Nikitenko A.V. Vasiliy Andreevich Zhukovskiy so storony ego poeticheskogo kharaktera i deyatel'nosti [Vasily Zhukovsky from his poetic nature and activities]. St. Petersburg, 1853.

17. Belinsky V.G. Polnoye sobraniye sochineniy: v 13 t. [Complete Works: in 13 v.]. Moscow: USSR AS Publ., 1953. V. 3, 684 p.

Received: 25 March 2015 